University of Wollongong

Research Online

Faculty of Business - Papers (Archive)

Faculty of Business and Law

2019

Carer Factors Associated with Foster-Placement Success and Breakdown

Leonie M. Miller

University of Wollongong, leoniem@uow.edu.au

Melanie J. Randle

University of Wollongong, mrandle@uow.edu.au

Sara Dolnicar

University of Queensland, s.dolnicar@uq.edu.au

Follow this and additional works at: https://ro.uow.edu.au/buspapers

Part of the Business Commons

Research Online is the open access institutional repository for the University of Wollongong. For further information contact the UOW Library: research-pubs@uow.edu.au 


\title{
Carer Factors Associated with Foster-Placement Success and Breakdown
}

\author{
Abstract \\ The characteristics of carers in successful foster placements are identified to enable targeting them \\ through customised marketing and recruitment campaigns. A longitudinal study with seventy-five carers \\ was conducted over twenty months. Eleven instances of placement breakdown were compared to \\ placements that did not break down. Several personal and family factors were identified as increasing the \\ likelihood of foster-placement success, including higher cognitive empathy of the carer, a high level of \\ social support from family, a high-quality carer-partner relationship, higher levels of care-giving and role- \\ carer demand satisfaction, and a good match, fewer conflicts and better relationship between the carer \\ and foster child. Conflicts between the carer and the child mediate the association between carer-partner \\ relationship quality and carer satisfaction with role demands. Findings have important practical \\ implications: additional evaluations should be conducted during screening processes with a focus on the \\ key markers of placement success identified in this study; more emphasis should be placed on \\ developing support networks amongst carers' friends and family; and greater involvement of carer \\ partners in screening and training processes is of key importance. \\ Disciplines \\ Business \\ Publication Details \\ Miller, L., Randle, M. \& Dolnicar, S. (2019). Carer Factors Associated with Foster-Placement Success and \\ Breakdown. The British Journal of Social Work, 49 (2), 503-522.
}

This journal article is available at Research Online: https://ro.uow.edu.au/buspapers/1486 


\title{
Carer factors associated with foster placement success and breakdown
}

\begin{abstract}
The characteristics of carers in successful foster placements are identified to enable targeting them through customised marketing and recruitment campaigns. A longitudinal study with 75 carers was conducted over 20 months. Eleven instances of placement breakdown were compared to placements which did not break down. Several personal and family factors were identified as increasing the likelihood of foster placement success, including higher cognitive empathy of the carer, a high level of social support from family, a high quality carer-partner relationship, higher levels of caregiving and role carer demand satisfaction, and a good match, fewer conflicts and better relationship between the carer and foster child. Conflicts between the carer and the child mediate the association between carer-partner relationship quality and carer satisfaction with role demands. Findings have important practical implications: additional evaluations should be conducted during screening processes with a focus on the key markers of placement success identified in this study; more emphasis should be placed on developing support networks amongst carers' friends and family; and greater involvement of carer partners in screening and training processes is of key importance.
\end{abstract}

Keywords: foster care, placement breakdown, longitudinal study 
Foster care can offer a safe and stable home to children who cannot live with their biological families (Harkin and Houston, 2016). Foster children often have complex histories, trauma experiences, disabilities or disorders, face difficult family circumstances such as drug abuse and, as a consequence, are more likely to have developmental deficits in emotional processing and problem solving (Khoo and Skoog, 2014; Harkin and Houston, 2016). Foster placement stability and the formation of trust and healthy attachment with adult caregivers are crucial for the development and well-being of foster children (Newton et al., 2000). But each foster placement also exposes a child to the possibility of placement breakdown. Breakdowns can be unexpected, unwelcome and rejecting for the child (Rostill-Brookes et al., 2011) and leave children feeling disempowered (Sinclair et al., 2005; Rostill-Brookes et al., 2011). They feel a sense of failure (Minty, 1999), can lose trust in adults (Butler and Charles, 1999), and may lose confidence in the possibility of forming an attachment to caregivers, instead they come to anticipate that all attachment relationships will result in rejection and disconnection (Strijker et al., 2008). It is common for children to experience behavioural and emotional difficulties (Newton et al., 2000) which can lead to a child rejecting carers, or being rejected by carers. Each placement breakdown can start a "vicious circle of breakdown and behavioural and psychological pathology" in the child (Oosterman et al., 2007, p.54), a result which stands in stark contrast to the objectives of the foster care system and intentions of administrators, caseworkers and carers. Furthermore, these types of experiences can lead to a range of longer-term consequences for the foster child, including poorer educational and health outcomes, and greater likelihood of homelessness and criminal activity as adults (Gilbertson and Barber, 2003).

Placement breakdowns come at high cost for foster care organisations (Pattern, 2005 in Brown and Bednar, 2006). New carers need to be recruited but this is exceptionally difficult and expensive; only about two percent of foster carer enquires result in the individual becoming a carer and having a child placed with them (Delfabbro et al., 2008). This is due to a range of 
factors including the unrealistic expectations of potential carers, the screening out of applicants by foster care agencies and a lack of targeted marketing. Such a broad-brush approach reaches many people who would never even consider becoming a foster carer (estimated to be around 55 percent of the Australian population, Ciarocchi et al., 2012). In addition, increased levels of support are often required for new placements, especially if a placement disruption has occurred just prior. In this case, additional costs are incurred by the agency in terms of providing the appropriate supports for both the child and the carer.

\section{THE TARGET SEGMENT OF HIGH PERFORMING FOSTER CARERS}

A number of studies have attempted to identify the distinct socio-demographic characteristics of high performing foster carers: some suggest older carers perform better (Walsh and Walsh, 1990), however age does not emerge consistently as a success factor and, overall, there is little evidence to suggest that high performing foster carers have a distinct socio-demographic profile.

Some psychological constructs, such as concern for children (Buehler et al., 2003; Harkin and Houston, 2016), genuine desire to help the child and include them as part of the family (Randle, 2013), a capacity to set boundaries, maintain consistency in routine, yet demonstrate flexibility (Rock et al., 2015), have been related to improved placement outcomes. In particular, a carer's ability to understand why a child responds to circumstances the way they do (Buehler et al., 2003) and to not reject the child on the basis of their behaviour, is a key factor (Sinclair and Wilson, 2003; Sinclair et al., 2005). A carer's warmth and affection toward the child also affects placement stability (Sinclair and Wilson, 2003; Oosterman et al., 2007), as does their level of satisfaction with the foster caring role (Denby et al., 1999; Randle et al., under review).

One study obtained data from carers directly (see Sinclair and Wilson, 2003; Sinclair et al., 2005) and examined the validity of a model of placement breakdown that focused on characteristics of 
the child, the carer, and the child-carer relationship. Measures were taken from 472 carers, social workers and placement workers over a period of 14 months. Carers were rated on the dimensions of capacity to care, acceptance, clarity of expectation, reaction to lack of response from the child, and capacities to view situations from the child's perspective and offer encouragement. A further measure of child-carer relationship (a rejection score) was taken from carers and indicated how fond the carer was of the child, and/or whether the child was considered difficult to manage. The authors identified that breakdown could be predicted using both the parenting score, which combined the social and placement workers' scores across dimensions, and the rejection score.

In relation to the foster child, behavioural problems emerge as a primary factor in placement breakdowns (Newton et al., 2000; Oosterman et al., 2007; Rock et al., 2015; van Santen, 2015) because of the high demands on carers and families (Khoo and Skoog, 2014). However, the effect is small across studies, and decreases with the age of children (Oosterman et al., 2007).

It has long been recognised that good 'placement match' - the strength of connection between the child and his or her carers - is of critical importance (Gilbertson and Barber, 2003; Sinclair and Wilson, 2003; Brown and Bednar, 2006; Khoo and Skoog, 2014; van Santen, 2015; Harkin and Houston, 2016). High level commitment, good communication by the carer, and the ability to help children with difficult feelings (Buehler et al., 2003; Rock et al., 2015) are associated with carer satisfaction, carer well-being and carer intention to continue fostering (Whenan et al., 2009).

The review of literature reveals variation in how researchers consider and define high performing foster carers. Most commonly, placements are considered successful if they last as intended and do not break down, and the characteristics of carers in such placements has received much research attention (e.g. Sinclair et al., 2005; Oosterman et al., 2007; Rock et al., 2015). For the present study, high performing foster carers are defined as those whose placements do not breakdown during the study period. 


\section{SPILLOVER HYPOTHESIS}

Within a family system, the spillover hypothesis refers to the phenomenon where the psychological costs arising from one family relationship affects functioning in another (Nelson $e t$ $a l ., 2009)$. Specifically, the quality of the marital or cohabiting relationship influences a parent's ability to assist a child in managing and understanding their emotions, particularly negative feelings. If extended to foster care, this hypothesis predicts that better circumstances in other areas of a carer's personal situation and family system leads to fewer conflicts with the foster child. Given that foster children often struggle with emotion regulation (Barth et al., 2007), coupled carers may be especially sensitive to personal and relationship issues spilling over to the foster care relationship.

Some support for this hypothesis comes from prior research investigating the relationship between the carer and their partner. Placements where the foster father is emotionally involved are more stable (Walsh and Walsh, 1990); and the length of the partner relationship is negatively associated with placement breakdowns (Walsh and Walsh, 1990). Feedback from carers further points to the importance of a strong co-operative relationship between coupled carers (Buehler et al., 2003). In addition, carers who have good relationships with extended family (Walsh and Walsh, 1990; Kalland and Sinkkonen, 2001) or good social support networks (Beek and Schofield, 2002) offer more stable foster placements. Conversely, carer burnout reduces carer ability to help a foster child with their feelings (Buehler et al., 2003; Piko, 2006).

The present study aimed to define the optimal target market of foster carers by identifying (1) whether personal attributes of foster carers - including a number of interpersonal capacities and personal resources - are associated with a reduced likelihood of placement breakdown (Buehler et al., 2003), and (2) whether family relationships - including the relationship of the couple fostering 
the child and the relationship between child and foster carers - are associated with the likelihood of placement breakdown (Oosterman et al., 2007).

The answers to these questions will enable targeting of potential foster carers whose personal and family circumstances make them better equipped to deal with the pressures of the role and therefore be resilient in the role, reducing the likelihood of placement breakdown. In turn, this will provide better outcomes for foster children and contribute to the greater effectiveness of the foster care system. Therein lies the practical value of this study. Its theoretical contribution lies in (1) proposing what is arguably the most complex foster carer segmentation base: personal and relationship factors identified longitudinally to be associated with placement stability, and (2) extending the spillover hypothesis, proposed in family psychology, which argues that tensions between a subset of family members spill over and burden other parts of the family system, to the foster caring context.

\section{METHOD}

The current study extends on the work by Sinclair and Wilson (2003) and Sinclair et al. (2005). It was conducted in Australia, where foster care placements are funded by government and managed by both government and non-government agencies. Individual foster care agencies provide the supports associated with each placement, and most allocate a caseworker to each placement who takes responsibility for supporting both the carer and the child, and monitoring the child's wellbeing, progress and outcomes.

\section{Fieldwork administration}

Foster carers were recruited through the Australian Foster Care Association and local foster care agencies. Foster care agencies were contacted directly and asked to forward an invitation to participate in the study to their carers. Interested carers then contacted the researchers directly and 
provided their contact details. Participants were then either emailed a link to the online survey or posted a paper survey, in both cases their survey contained a unique identifier that enabled individual responses in different waves of data collection to be linked. Although respondents were drawn predominately from metropolitan, regional and rural areas of New South Wales (68\%), respondents from several other jurisdictions chose to participate in the study (Australian Capital Territory, Northern Territory, Queensland, South Australia and Victoria). The baseline survey took place from May 2011 to February 2012 and included multiple psychological test batteries and questions about the foster carers and their foster caring experience. The subsequent four data collection waves occurred in four month intervals. Questions focused on the status of the placement and any changes since the last wave of data collection (including whether the placement had broken down since the last wave, and if so the circumstances of that placement ending), and carers' level of satisfaction with various aspects of their role. The research protocol was approved by the university Human Research Ethics Committee (HE10/067) prior to data collection commencing.

\section{INSERT FIGURE 1 ABOUT HERE}

\section{Measures}

The measures used in this study were subsets of the measures taken at baseline and each of the follow-up waves. Unless otherwise indicated, measures are baseline only.

Carer characteristics served as descriptor variables. Carers reported on their age, sex, ethnicity, relationship status and level of education $(1=$ no secondary high school qualification, $\ldots, 8=$ postgraduate qualification). The Parenting Sense of Competence Scale (PSOC, Gibaud-Wallston and Wandersman, 1978; as cited by Johnston and Mash, 1989) was used to measure caregiving competence. Carers were asked to respond to 14 items on a 6-point agreement scale. Items were modified to the context of foster caring. Caregiving satisfaction and efficacy subscales were 
derived from this measurement, with lower scores indicating greater satisfaction and efficacy respectively. The Basic Empathy Scale (BES, Jolliffe and Farrington, 2006) comprises 20 items with responses made on a 5-point agreement scale. Higher scores indicate greater empathy. The Multidimensional Scale of Perceived Social Support (MSPSS; Zimet et al., 1988) measured perceived social support. Twelve items were responded to using a 7-point agreement scale. Carerpartner relationship quality was measured by asking five items about the degree of satisfaction, seriousness of problems, happiness experienced and how much they love their spouse or partner (Fletcher et al., 2000; Ciarocchi et al., 2012). Items were rated on a 7-point scale with higher scores indicating better relationship quality. Carers were asked to rate the quality of the placement match between themselves and their foster child on a 5-point scale.

A number of child-related measures were included as control variables at baseline, including the child's demographic characteristics, perceived progress of the child rated on a five-point scale, and a behavioural measure (Strengths and Difficulties Questionnaire; Goodman, 1997). This last instrument contains several subscales (emotional symptoms, conduct problems, hyperactivity, peer problems and prosocial behaviours), that are each aggregates of 10 items measured on a 4point scale. Measures of support from the foster care system served as a second set of control variables. These measures comprised six different supports: quality of caseworkers $(1=$ Excellent, .., $5=$ Very poor), agency support (five items measured on a scale from $1=$ a lot less than needed, $\ldots, 5=$ a lot more than needed $)$, the number of training courses (0-9), financial allowance $(1=$ more than enough, ..., 4 = a lot less than needed), respite (number of days in the previous 4 months $)$ and government agency support $(1=$ very dissatisfied, $\ldots, 5=$ very satisfied $)$.

The following measures were taken at baseline and each subsequent wave. Overall satisfaction with foster caring was measured using the Satisfaction with Foster Parenting Inventory (SFPI, Leckies et al., 1997). Responses range from $1=$ very dissatisfied to $5=$ very satisfied. The original scale has 22 items with three subscales: role demands, social support services and personal needs. 
Administration involved two modifications: (1) to better differentiate sources of satisfaction with the items relationship with your foster care agency, caseworker and government agency, three separate items focussed on each source; and (2) a series of items were added sampling satisfaction with child progress, carer rights, confidence in the ability to care, social support, and satisfaction with life overall. The Parent-Child Relationship Scale (P-CRS; Pianta, 1995) was adapted to focus on the relationship between the carer and foster child over the previous four months. This 15 -item measure has two subscales - conflicts and closeness - with responses on a 5-point scale. Higher scores indicate greater conflicts or closeness with the child.

Carers were asked whether the placement had changed since the last data collection wave. If it had changed, carers provided details regarding the end of the placement, including whether or not it had ended as originally planned, who decided to end the placement, and where the foster child went after the placement ended. These details were independently assessed by the first and second authors who determined whether it qualified as a 'placement breakdown' or a 'non-breakdown placement change'. Those categorised as a 'placement breakdown' had discontinued and were also considered to have been unsuccessful (these elements reflect the two criteria used by Sinclair and Wilson (2003) to define placement success, namely (1) if the placement had broken down and (2) if it was rated as successful or not). Placements categorised as a 'non-breakdown placement change' had discontinued but did not meet the above two criteria (e.g. they may have ended but still been considered successful for other reasons such as early reunification with the birth family). In the case of any discrepancy between the independent assessors, agreement was achieved by revisiting the carer remarks. Placement breakdown served as a dependent variable in this study.

\section{Analysis}

Internal consistencies of scale measures are presented in Table 1. These values ranged from .55.96 , with all but two scales' consistencies considered to be acceptable. Group comparisons of 
scale measures were conducted using $t$-tests, unless a measure's data was identified as nonnormal, in which case the corresponding nonparametric test (Mann-Whitney $U$ test) was used. Comparisons of variables expressed as frequency counts (e.g. carer sex) were made using Fisher's exact test. Due to the low statistical power of this sample, the significance criterion was maintained at $\alpha=.05$.

INSERT TABLE 1 ABOUT HERE

\section{RESULTS}

\section{Sample}

Initially, 212 foster carers (corresponding to 143 placements) consented to participate in, at a minimum, the baseline survey and reported on the eldest child currently in care. The majority of these carers continued to provide data in at least some of the subsequent waves of data collection. The study sample was reduced to 75 because of a number of constraints on the data resulting in 64 continuing and 11 breakdown placements across the 20 months. Figure 1 outlines how these constraints were applied to the data set and describes the study sample. Exclusion criteria included omitting placements with children younger than 2 years, as these were deemed caring contexts that were (i) unlikely to encounter placement breakdown (Kalland and Sinkkonen, 2001), and (ii) could produce inaccurate or inconsistent data from measures designed to assess behaviour in older children (Whenan et al., 2009). Instances of respite care were also omitted because of the intermittent nature of care. Overall, the study sample exhibited features consistent with the population of carers, namely they were on average, middle aged, and if a single carer more likely to be female.

\section{Characteristics of successful foster carers}


Table 1 summarises the comparisons between breakdown and non-breakdown groups and provides means and standard deviations (in parentheses) of scale measures, and contingency tables of frequency measures. Significant differences are marked with an asterisk (*) and effect sizes are reported to assist the reader in appraising the relative importance of effects as they arose in the present study. In terms of carer characteristics, the ratio of male to female carers was higher in the breakdown than the non-breakdown group. Differences in the carer-related variables of cognitive empathy, social support from family, and the quality of relationship with a partner were found between breakdown and non-breakdown groups, with continuing placements reporting higher levels. Carers in continuing placements also reported higher levels of caregiving satisfaction and role demands satisfaction than the breakdown group. Carers of continuing placements assessed the placement match as better, and rated their relationship with the child as closer and lower in conflict, but there was no reliable difference between continuing and breakdown groups in ethnicity match between the carer and child. No significant differences were identified with respect to child characteristics. However, as an effect of the child's age may have been masked by non-significant differences in placement length, an estimate of the child's age at placement commencement was made by subtracting baseline measures of placement length from the child's age. The placement commencement age $(M=5.54, S D=3.88)$ was significantly lower for continuing $(M=5.54, S D=3.88)$ than breakdown $(M=8.48, S D=3.59)$ cases, $t(73)=-2.34$, $p=.02, d=-0.77$.

\section{INSERT TABLE 2 ABOUT HERE}

Correlations across the entire sample are presented in Table 2. Several factors are interrelated and in line with findings in prior literature: there is a negative association between the relationship quality with a carer's partner and both conflict with the child, and a positive association between relationship quality and satisfaction with role demands; cognitive empathy is positively associated with the level of closeness of carer and child; and family social support is negatively associated 
with conflicts with the child and but positively satisfaction with caregiving and role demands as a carer. These associations support the notion that factors of placement breakdown do not work in isolation.

\section{The spillover hypothesis}

A mediation model of the spillover hypothesis with elements of burnout theory is proposed, which suggests that the association between quality of relationship with a carer's partner and satisfaction with the demands of the role should be mediated by the level of conflict with the foster child (see Figure 2). It is argued that spillover is more likely to occur from the relationship between carer partners to conflicts with the child than vice versa, despite the measurement of relationship quality when children were already placed, as there were no reliable differences in child behavioural variables between breakdown and continuing groups.

Single-carers were excluded from the data set for this analysis $(N=54)$. New data was used to test this hypothesis: two new variables were constructed using repeated measurements of the Conflicts subscale of the P-CRS (Pianta, 1995) and the Role Demands subscales of the Satisfaction with Foster Care scale (Leckies et al., 1997). For the conflicts measure, an average of all measurements was taken from baseline up to the point of breakdown. Satisfaction with role demands was measured prior to breakdown for breakdown cases, and at the last survey wave otherwise. The temporal sequence of measurements conforms to the logic of the mediation model: relationship quality acts as an antecedent to conflicts with the child, and both measures act as antecedents to the level of satisfaction with role demands. Lastly, the age of the foster child at placement commencement was included as a covariate.

\section{INSERT FIGURE 2 ABOUT HERE}

Mediation analysis was conducted using PROCESS (Hayes, 2012) which uses bias-corrected bootstrapping to determine the significance of the indirect effect in the model, namely whether the 
mediated route (conflicts with the child) can reliably explain variance that is otherwise attributed to the direct relationship between the independent variable (relationship quality with a partner) and the dependent variable (satisfaction with role demands of caring). The effect of age at placement commencement was controlled for in path analysis calculations. Bootstrapped confidence intervals were based on 10,000 bootstrap samples.

\section{INSERT TABLE 3 ABOUT HERE}

A summary of effects in the mediation model is presented in Table 3. The new role satisfaction measure produced a Cronbach's $\alpha$ of .68 (acceptable internal consistency). The total effect model, controlling for the effect of age at placement commencement, revealed that the relationship quality with a carer's partner was a significant predictor of the level of satisfaction with the role demands $c=.29, t(51)=2.60, p=.012$. Specifically, the more positively a carer viewed the relationship with their partner, the greater their satisfaction with role demands. This model explained $13 \%$ of the variance in role demands satisfaction, $F(2,51)=3.85, p=.028$. The results of the path analyses are given in Table 4. In the left set of columns it can be seen that relationship quality was a significant predictor of conflicts with the child $(a=-0.52), t(51)=-2.59 p=.013-$ the more positively a carer viewed the relationship with their partner, the lower the conflicts. In the right set of columns, conflicts with the child is a significant predictor of satisfaction with role demands $(b=-0.24), t(50)=-3.49, p=.001$, but relationship quality with the partner is not $\left(c^{\prime}=\right.$ $0.16), t(50)=1.51, p=.138$.

\section{INSERT TABLE 4 ABOUT HERE}

The indirect effect of conflicts with the child was significant; this effect $(a b=.13)$ explained a reliable component of variation in the total effect of relationship quality on role demand satisfaction (see 95\% confidence interval in Table 4). Specifically, for each unit decrease in relationship quality with a partner, there is a .13 decrease in the level of satisfaction with the role 
demands of being a carer, consistent with the increase of conflicts experienced with the child, arguably due to relationship spillover. The direct effect of relationship quality on satisfaction with role demands was not statistically different from zero, with $95 \%$ confidence. Thus, the variation in role demands satisfaction explained by variation in relationship quality when conflicts with the child is considered, was not reliable.

\section{DISCUSSION}

The current research has identified several carer-centric factors that may actively contribute to foster placement success or breakdown. Carers in continuing placements reported greater capacity to understand the emotional reactions of others (cognitive empathy), lending evidence to qualitative insights gained from carers (Buehler et al., 2003). The potential for tensions to exist between carer and foster child when the carer is unable to adjust their expectations of the child during developmental change, especially with adolescents, has been noted (Rostill-Brookes et al., 2011). Furthermore, the positive relationship between cognitive empathy and closeness with the child suggests that understanding the emotional response of another aids in forging a stronger sense of connection (Buehler et al., 2003).

Some carer-related factors are more circumstantial. Greater support from family was associated with fewer breakdowns, in line with prior findings (Walsh and Walsh, 1990; Kalland and Sinkkonen, 2001). Broader social support networks are associated with many benefits, particularly psychological resilience, and the availability of others to help out gives carers more options to free up resources required for caring (Cohen and Wills, 1985). Correlations between variables identified that greater social support was associated with lower levels of conflict with the child and greater satisfaction of both caregiving and the role demands of caregiving.

The idea that a carer's resource availability depends on circumstances also fits with the finding 
that carers with more positive relationships with their partner were less likely to experience placement breakdowns. The effect size for this variable is very large $(d=1.47)$. It is plausible that a good relationship maximises the capacity to deal effectively with emotional needs of the child (Cummings and Davies, 2002). Additionally, carers that demonstrate functional interaction with each other can provide the foster child with a relational model that reinforces acceptance, sharing and trust.

Other care-giver variables revealing differences between groups were associated with satisfaction with either caregiving itself, or the role demands associated with being a foster carer. That these baseline measures predicted later breakdown is consistent with the lengthy consideration that often occurs prior to actual breakdown (Randle et al., 2016). If a carer feels unable to derive a sense of well-being from caring, it may indicate their low capacity to deal with challenges and may contribute to a crisis in future (Whenan et al., 2009).

Correlations between the variables distinguishing breakdown from non-breakdown groups also identified that the carer factor of relationship quality with the partner is negatively related to the level of conflicts experienced in the relationship with the child, and positively related the level of satisfaction in the role demands of being a foster carer. This pattern of results was confirmed in a mediation model that used new data. These results are also consistent with the spillover of marital or cohabiting relationship hostility to parental hostility that was found to be associated with child aggression longitudinally, in a sample of adoptive parents and their children (Stover et al., 2016).

The results offer evidence that for coupled carers, in line with the spillover hypothesis, relationship quality can limit available psychological resources to deal with the foster caring role. Relationship quality influences whether a carer can effectively manage the child's negative affect and, as a consequence, contributes to the degree that the relationship is conflict-ridden. In turn, greater conflict with the child taxes the already limited psychological capacity of the carer, resulting in lower tolerance for role demands, and lower satisfaction. Accordingly, this series of 
effects presents a feasible mechanism that contributes to the positive association between relationship quality with a carer's partner and role demands satisfaction.

A number of factors in this study did not replicate earlier reports. In particular, the finding that behaviour of the child was not related to placement breakdown stands in contrast to previous research (e.g. Oosterman et al., 2007; Rock et al., 2015). However, children in non-breakdown placements were placed into care younger than those in the breakdown group. Speculatively, the reported behaviour of the child may reflect differences in the capacity of carers to deal with agerelated behaviour, as a function of the age of the child at start of placement.

Finally, previous reports of foster carer perspectives of breakdown have highlighted a need for greater agency and system support (e.g. Gilbertson and Barber, 2003), although no difference between groups was found in this study. It is possible that - as resources become increasingly stretched - all carers need more support but this issue is more salient in the case of placement breakdown. Nonetheless, as a consequence of these null findings, the study represents an opportunity to examine carer-centric factors in a context that is not highly confounded with other variables.

Limitations of this study include a small sample size which is due to the difficulties with recruitment and the long duration of the study. Also, selection bias may be present given voluntary participation. Given that the rate of breakdown was lower than reported in other studies (15\%), it can be assumed that carers participating in this study had a higher than average level of caring ability. Factors not measured here could also affect breakdowns, including problems between the child and a carer's partner or attachment difficulties with the child brought about by ongoing instability in birth family relationships. Foster children can also sabotage placements (Rostill-Brookes et al., 2011), making breakdown independent of carer characteristics. The number of tests involved in the preliminary comparisons was large. Results in Table 1 were not adjusted for multiple testing because they were exploratory in nature. However, a subsequent 
mediation analysis was supported by data, suggesting that differences shown in Table 1 are likely to be generalisable, and the theoretical arguments used to conceptualise these relationships are valid. Another limitation is the use of self-report measurement and the retrospectivity of some variables that are subject to cognitive biases such as forgetting and social desirability. However, the prospective nature of the study goes partway to countering concerns associated with the effects of such biases on the results, as cases were contrasted on the basis of actual outcome. Nonetheless, factors previously reported to predict breakdown may be insignificant here due to the attenuation of effects derived from self-report induced measurement biases. Finally, it should be noted that baseline measures for this study were taken after placements had already commenced. Future research could collect baseline data prior to placements commencing and then longitudinal data from then on to track the placement's progress.

This study extends previous research by contributing to the background knowledge necessary to satisfy the "urgent need to increase the supply of carers from whom to select" (Sinclair and Wilson, 2003) and create optimal matches with foster children. It does this by providing insight that foster care agencies can use to develop targeted marketing and recruitment campaigns. Past research has established that consumers respond more favourably to messages and imagery that reflect their own identity (Jaffe, 1991; Oakenfull and Greenlee, 2005). That high performing carers are likely to have higher levels of cognitive empathy suggests that promotions emphasising empathetic messages are likely to resonate with them. Promotions should also feature harmonious relationships with partners and children and strong support from family and friends.

Findings also have immediate practical implications for public policy makers and foster care agencies, although we acknowledge these recommendations are not always easy to implement given the very high demand for foster carers and the fact that any family situation is unique: First, during the screening of foster carers key markers of success identified in this study, such as cognitive empathy, could be assessed. Second, during screening and training of new foster carers, 
more emphasis could be placed on the development and nurturing of social support from family and friends by encouraging their participation in training, where simple ways of helping the carer could be discussed. Finally, given the importance of relationship quality of the carer with their partner in minimising breakdowns of foster care relationships, partners should also be actively involved in the training phase. During the placement, agencies could offer supervision sessions for the couples caring for a foster child in an attempt to prevent relationship issues translating into conflicts with the child which, in turn, negatively affects the relationship quality with the child.

\section{CONCLUSIONS}

Key carer factors identified in this study as being associated with foster care placement breakdown include lower levels of cognitive empathy; lower levels of family support; less positive relationship of the foster carer with their partner; lower satisfaction with caregiving and the role of being a foster carer. Results also support the notion underlying the spillover hypothesis that relationship quality of couples who foster a child jointly, affects the psychological resources required when fostering a child. Conflict with the child mediates the association between a carer's relationship quality with their partner and the level of satisfaction with the role demands as a carer. This finding is consistent with the claim that poor partner relations limit a carer's capacity to deal with the negative affect of the foster child. The model also points to the potential for carers to be vulnerable to burnout (Brown and Bednar, 2006; Whenan et al., 2009) because diminished satisfaction with a role, in combination with limited resources to deal with role demands, are known precursors of this condition.

Contrary to findings from prior studies, the foster child's behaviour was not associated with placement breakdowns. Child behaviour may still, however, indirectly lead to placement breakdown (Newton et al., 2000; Oosterman et al., 2007; Rock et al., 2015; van Santen, 2015) 
because it affects the quality of relationship of a carer with their partner. Accordingly, the results of this study may highlight a carer relationship dynamic that more generally can operate in tandem with, and receive feedback from, relational stresses due to child behaviour. Evidence to support a model of this kind would require cross-lagged panel data over multiple time points and is a potential direction for future research. 


\section{References}

Barth, R.P., Lloyd, E.C., Green, R.L., James, S., Leslie, L.K. and Landsverk, J. (2007) 'Predictors of Placement Moves among Children with and without Emotional and Behavioral Disorders', Journal of Emotional and Behavioural Disorders, 15(1), pp. 46-55.

Beek, M. and Schofield, G. (2002) 'Foster Carers' Perspectives on Permanence: A Focus Group Study', Adoption \& Fostering, 26(2), pp. 14-27.

Brown, J.D. and Bednar, L.M. (2006) 'Foster Parent Perceptions of Placement Breakdown', Children and Youth Services Review, 28(12), pp. 1497-1511.

Buehler, C., Cox, M.E. and Cuddeback, G. (2003) 'Foster Parents' Perceptions of Factors That Promote or Inhibit Successful Fostering', Qualitative Social Work, 2(1), pp. 61-83.

Butler, S. and Charles, M. (1999) 'The Past, the Present, but Never the Future: Thematic Representations of Fostering Disruption', Child and Family Social Work, 4(1), pp. 9-20. Ciarrochi, J., Randle, M., Miller, L. and Dolnicar, S. (2012) 'Hope for the Future: Identifying the Individual Difference Characteristics of People Who Are Interested in and Intend to Foster Care', British Journal of Social Work, 42(1), pp. 7-25.

Cohen, S. and Wills, T.A. (1985) 'Stress, Social Support and the Buffering Hypothesis', Psychological Bulletin, 98(2), pp. 310-357.

Cummings, E.M. and Davies, P.T. (2002) 'Effects of Marital Conflict on Children: Recent Advances and Emerging Themes in Process-Oriented Research', Journal of child psychology and psychiatry, 43(1), pp. 31-63.

Delfabbro, P., Borgas, M., Vast, R. and Osborn, A. (2008) 'The Effectiveness of Public Foster Carer Recruitment Campaigns: The South Australian Experience', Children Australia, 33(3), pp. 29-36.

Denby, R., Rindfleisch, N. and Bean, G. (1999) 'Predictions of Foster Parents' Satisfaction and Intent to Continue to Foster', Child Abuse and Neglect, 23(3), pp. 287-303. 
Fletcher, G.J., Simpson, J.A. and Thomas, G. (2000) 'The Measurement of Perceived Relationship Quality Components: A Confirmatory Factor Analytic Approach', Personality and Social Psychology Bulletin, 26(3), pp. 340-354.

Gilbertson, R. and Barber, J. (2003) 'Disrupted Adolescents in Foster Care: Their Perspectives on Placement Breakdown', Children Australia, 28(4), pp. 25-30.

Goodman, R. (1997) 'The Strengths and Difficulties Questionnaire: A Research Note', Journal of child psychology and psychiatry, 38(5), pp. 581-586.

Harkin, C. and Houston, S. (2016) 'Reviewing the Literature on the Breakdown of Foster Care Placements for Young People: Complexity and the Social Work Task', Child Care in Practice, pp. 1-15.

Hayes, A.F. (2012) Process: A Versatile Computational Tool for Observed Variable Mediation, Moderation, and Conditional Process Modeling, Available from http://www.afhayes.com/public/process2012.pdf, accessed

Jaffe, L.J. (1991) 'Impact of Positioning and Sex-Role Identity on Women's Responses to Advertising', Journal of Advertising Research, 31(3), pp. 57-64.

Johnston, C. and Mash, E.J. (1989) 'A Measure of Parenting Satisfaction and Efficacy', Journal of Clinical Child Psychology, 18(2), pp. 167-175.

Jolliffe, D. and Farrington, D.P. (2006) 'Development and Validation of the Basic Empathy Scale', Journal of Adolescence, 29(4), pp. 589-611.

Kalland, M. and Sinkkonen, J. (2001) 'Finnish Children in Foster Care: Evaluating the Breakdown of Long-Term Placements', Child Welfare, 80(5), pp. 513-527.

Khoo, E. and Skoog, V. (2014) 'The Road to Placement Breakdown: Foster Parents' Experiences of the Events Surrounding the Unexpected Ending of a Child's Placement in Their Care', Qualitative Social Work, 13(2), pp. 255-269.

Leckies, K.S., Yates, A.M., Crase, S.J. and Stockdale, D.F. (1997) 'Satisfaction with Foster 
Parenting Inventory', in Stockdale, D.F., Crase, S.J., Lekies, K.S., Yates, A.M. and GillisArnold, R. (eds), Manual for Foster Parent Research Measures: Motivations for Foster Parenting Inventory, Attitudes toward Foster Parenting Inventory, and Satisfaction with Foster Parenting Inventory, Ames, IA, Iowa State University.

Minty, B. (1999) 'Annotation: Outcomes in Long-Term Foster Family Care', Journal of child psychology and psychiatry, 40(7), pp. 991-999.

Nelson, J.A., O’Brien, M., Blankson, A.N., Calkins, S.D. and Keane, S.P. (2009) 'Family Stress and Parental Responses to Children's Negative Emotions: Tests of the Spillover, Crossover, and Compensatory Hypotheses', Journal of Family Psychology, 23(5), p. 671.

Newton, R.R., Litrownik, A.J. and Landsverk, J.A. (2000) 'Children and Youth in Foster Care: Disentagling the Relationship Betweeen Problem Behaviours and Number of Placements', Child Abuse and Neglect, 24(10), pp. 1363-1374.

Oakenfull, G.K. and Greenlee, T.B. (2005) 'Queer Eye for a Gay Guy: Using Market-Specific Symbols in Advertising to Attract Gay Consumers without Alienating the Mainstream', Psychology \& Marketing, 22(5), pp. 421-439.

Oosterman, M., Schuengel, C., Slot, N.W., Bullens, R.A.R. and Doreleijers, T.A.H. (2007) 'Disruptions in Foster Care: A Review and Meta-Analysis', Children and Youth Services Review, 29(1), pp. 53-76.

Pianta, R.C. (1995) Parent-Child Relationship Scale (P-Crs), Charlottesville, Virginia, Curry School of Education, University of Virginia.

Piko, B.F. (2006) 'Burnout, Role Conflict, Job Satisfaction and Psychosocial Health among Hungarian Health Care Staff: A Questionnaire Survey', International Journal of Nursing Studies, 43(3), pp. 311-318.

Randle, M. (2013) 'Through the Eyes of Ex-Foster Children: Placement Success and the Characteristics of Good Foster Carers', Practice: Social Work in Action, 25(1), pp. 3-19. 
Randle, M., Ernst, D., Leisch, F. and Dolnicar, S. (2016) 'What Makes Foster Carers Think About Quitting? Recommendations for Improved Retention of Foster Carers', Child \& Family Social Work, 22(3), pp. 1175-1186.

Randle, M., Miller, L., \& Dolnicar, S. 'What can agencies do to increase foster carer satisfaction?' Child \& Family Social Work, Advance Access published September 21, 2017, https://doi.org/10.1111/cfs.12402

Rock, S., Michelson, D., Thomson, S. and Day, C. (2015) 'Understanding Foster Placement Instability for Looked-after Children: A Systematic Review and Narrative Synthesis of Quantitative and Qualitative Evidence', British Journal of Social Work, 45(1), pp. 177-203. Rostill-Brookes, H., Larkin, M., Toms, A. and Churchman, C. (2011) 'A Shared Experience of Fragmentation: Making Sense of Foster Placement Breakdown', Clinical Child Psychology and Psychiatry, 16(1), pp. 103-127.

Sinclair, I. and Wilson, K. (2003) 'Matches and Mismatches: The Contribution of Carers and Children to the Success of Foster Placements', British Journal of Social Work, 33(3), pp. $871-884$.

Sinclair, I., Wilson, K. and Gibbs, I. (2005) Foster Placements: Why They Succeed and Why They Fail, London, Jessica Kingsley Publishers.

Stover, C.S., Zhou, Y., Kiselica, A., Leve, L.D., Neiderhiser, J.M., Shaw, D.S., Natsuaki, M.N., Scaramella, L.V. and Reiss, D. (2016) 'Marital Hostility, Hostile Parenting, and Child Aggression: Associations from Toddlerhood to School Age', Journal of the American Academy of Child \& Adolescent Psychiatry, 55(3), pp. 235-242.

Strijker, J., Knorth, E.J. and Knot-Dickscheit, J. (2008) 'Placement History of Foster Children: A Study of Placement History and Outcomes in Long-Term Family Foster Care', Child Welfare, 87(5), pp. 107-124.

van Santen, E. (2015) 'Factors Associated with Placement Breakdown Initiated by Foster Parents 
- Empirical findings from Germany', Child and Family Social Work, 20(2), pp. 191-201.

Walsh, J.A. and Walsh, R.A. (1990) Quality Care for Tough Kids: Studies of the Mainenance of Subsidised Foster Placements in the Casey Family Program, Washington, DC, Child Welfare League of America.

Whenan, R., Oxlad, M. and Lushington, K. (2009) 'Factors Associated with Foster Carer WellBeing, Satisfaction and Intention to Continue Providing out-of-Home Care', Children and Youth Services Review, 31(7), pp. 752-760.

Zimet, G.D., Dahlem, N.W., Zimet, S.G. and Farley, G.K. (1988) 'The Multidimensional Scale of Perceived Social Support', Journal of Personality Assessment, 52(1), pp. 30-41. 


\section{Figure Legend}

Figure 1. Flowchart depicting the breakdown of carer cases in the longitudinal data set. Additional descriptive statistics of carer groups are listed in Table 1.

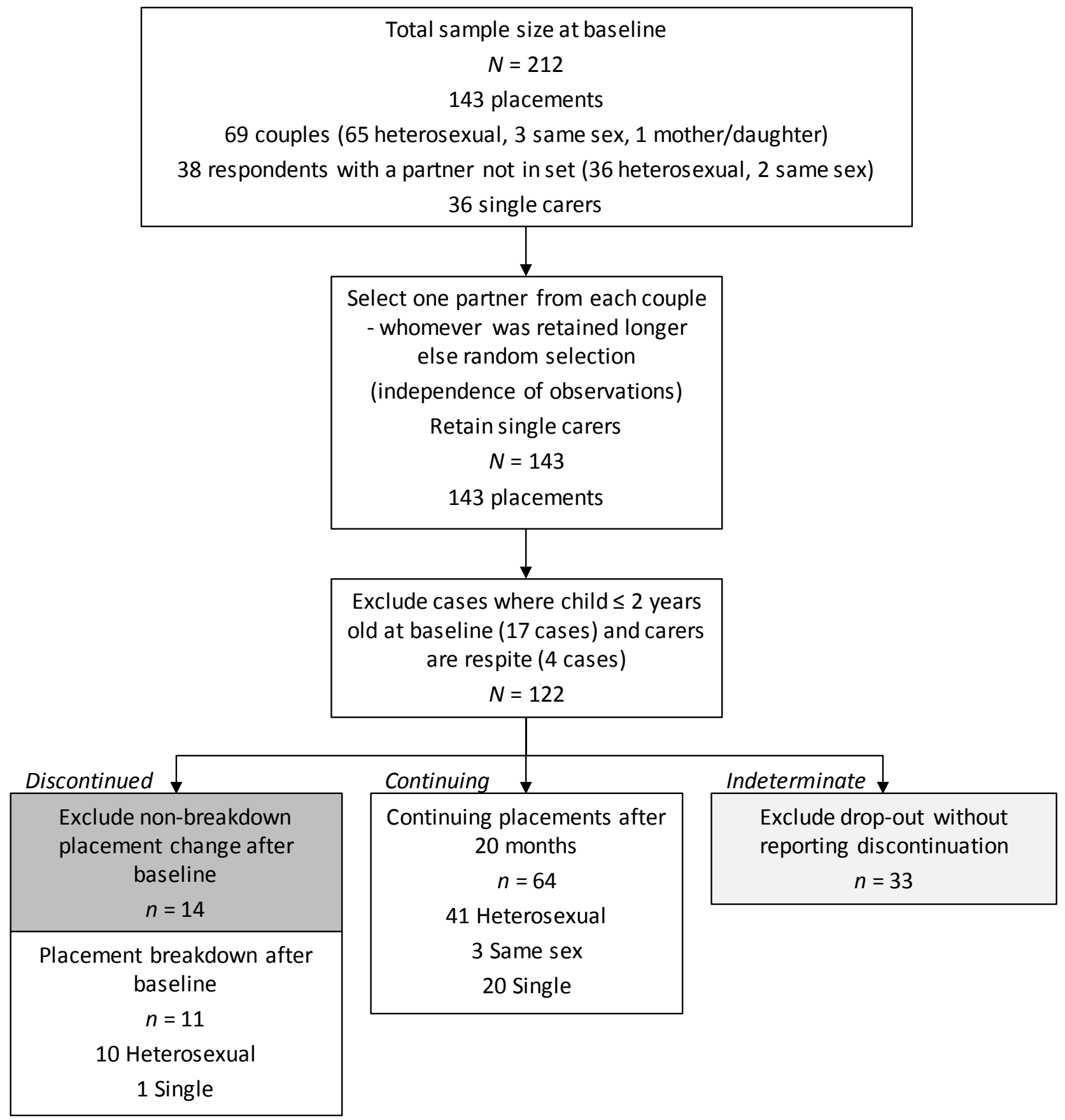


Figure 2. Mediation model of carer-child conflict on the association between carer-partner relationship quality and carer role satisfaction.

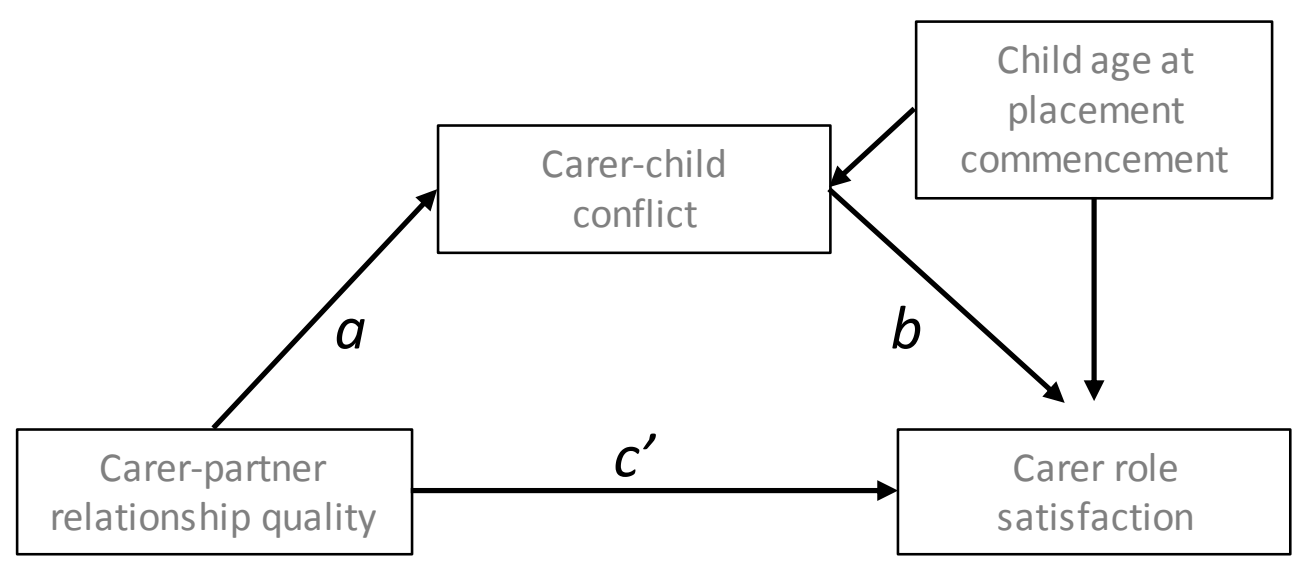




\section{Tables}

Table 1. Means and standard deviations or frequency counts of foster care factors, significance levels, and effect sizes of comparisons between continuing (non-breakdown) placement and breakdown placement groups.

\begin{tabular}{|c|c|c|c|c|c|}
\hline & $\begin{array}{c}\text { Cronbach } \\
\alpha \\
\end{array}$ & $\begin{array}{c}\text { Continuing } \\
\qquad N=64\end{array}$ & $\begin{array}{l}\text { Breakdown } \\
\quad N=11\end{array}$ & $p$ & $\begin{array}{c}\text { Effect } \\
\text { size }\end{array}$ \\
\hline Placement length (years) & - & $4.21(2.97)$ & $2.80(2.93)$ & 0.15 & 0.48 \\
\hline \multicolumn{6}{|l|}{ Carer characteristics } \\
\hline Age & - & $47.45(8.82)$ & $45.82(8.86)$ & 0.57 & 0.18 \\
\hline \multicolumn{6}{|l|}{ Sext } \\
\hline Male & & 19 & 7 & $0.04 *$ & 0.21 \\
\hline Female & & 45 & 4 & & \\
\hline \multicolumn{6}{|l|}{ Foster carer experience } \\
\hline Time in foster care (years) & - & $6.09(4.54)$ & $5.56(4.09)$ & 0.72 & 0.12 \\
\hline Number of placements $\dagger^{\mathrm{a}}$ & - & $14.20(23.11)$ & $14.18(14.46)$ & 0.36 & -0.11 \\
\hline Number of children cared for $\dagger^{a}$ & - & $12.53(18.71)$ & $14.82(13.87)$ & 0.25 & -0.13 \\
\hline Education level & - & $4.98(2.09)$ & $4.36(1.75)$ & 0.36 & 0.30 \\
\hline \multicolumn{6}{|l|}{ Caregiving competence (PSCOC) } \\
\hline Caregiving satisfaction & 0.82 & $26.20(5.80)$ & $21.55(7.19)$ & $0.02 *$ & 0.77 \\
\hline Caregiving efficacy & 0.81 & $34.69(6.20)$ & $33.27(6.99)$ & 0.49 & 0.22 \\
\hline \multicolumn{6}{|l|}{ Foster caring satisfaction (SFPI) } \\
\hline Caring role demands & 0.55 & $27.00(3.08)$ & $24.00(3.77)$ & $0.01 *$ & 0.94 \\
\hline Social services support & 0.81 & $14.78(3.77)$ & $14.73(4.17)$ & 0.97 & 0.01 \\
\hline Personal needs & 0.71 & $19.47(4.54)$ & $19.55(4.18)$ & 0.96 & -0.02 \\
\hline \multicolumn{6}{|l|}{ Empathy (BES) } \\
\hline Cognitive & 0.75 & $38.73(4.02)$ & $35.00(4.29)$ & $0.01 *$ & 0.92 \\
\hline Affective & 0.76 & $37.38(5.76)$ & $36.27(6.39)$ & 0.57 & 0.19 \\
\hline \multicolumn{6}{|l|}{ Social support (MSPSS) } \\
\hline Significant Other $\uparrow$ & 0.96 & $24.72(4.66)$ & $24.64(3.93)$ & 0.54 & -0.07 \\
\hline Family & 0.93 & $24.19(4.42)$ & $20.27(6.15)$ & $0.03 *$ & -0.25 \\
\hline Friends $\dagger$ & 0.93 & $23.69(3.82)$ & $23.82(4.14)$ & 0.79 & -0.03 \\
\hline Carer-partner relationship quality & 0.90 & $\begin{array}{c}(N=44) \\
31.91(3.71)\end{array}$ & $\begin{array}{c}(N=10) \\
25.60(6.83)\end{array}$ & $0.02 *$ & 1.47 \\
\hline Placement match & - & $1.52(0.71)$ & $2.00(0.78)$ & $0.04 *$ & -0.66 \\
\hline \multicolumn{6}{|l|}{$\begin{array}{l}\text { Ethnicity match between carer and } \\
\text { child } \ddagger\end{array}$} \\
\hline Yes & & 31 & 5 & 1.00 & 0.00 \\
\hline No & & 33 & 6 & & \\
\hline \multicolumn{6}{|l|}{ Carer-child relationship (P-CRS) } \\
\hline Conflicts & 0.86 & $19.52(7.79)$ & $26.00(8.10)$ & $0.01 *$ & -0.83 \\
\hline Closeness & 0.86 & $29.45(5.39)$ & $24.45(6.49)$ & 0.01 & 0.90 \\
\hline \multicolumn{6}{|l|}{ Child characteristics } \\
\hline \multicolumn{6}{|l|}{ Age } \\
\hline Years & - & $9.73(3.78)$ & $11.27(3.98)$ & 0.57 & -0.40 \\
\hline Range (years) & & $3-17$ & $3-16$ & & \\
\hline Sex & - & & & & \\
\hline Male & & 32 & 8 & 0.20 & 0.14 \\
\hline Female & & 32 & 3 & & \\
\hline Progress $\ddagger$ & - & & & & \\
\hline Below expected & & 13 & 5 & 0.12 & 0.16 \\
\hline Above expected or expected & & 51 & 6 & & \\
\hline
\end{tabular}




\begin{tabular}{|c|c|c|c|c|c|}
\hline \multicolumn{6}{|l|}{ Behaviour (SDQ) } \\
\hline Emotional symptoms & 0.68 & $3.06(2.46)$ & $3.55(1.04)$ & 0.28 & -0.21 \\
\hline Conduct problems & 0.76 & $3.53(2.68)$ & $4.64(2.87)$ & 0.22 & -0.41 \\
\hline Hyperactivity & 0.84 & $5.64(2.94)$ & $6.73(2.87)$ & 0.26 & -0.37 \\
\hline Peer problems & 0.69 & $3.72(2.42)$ & $4.00(2.61)$ & 0.73 & -0.11 \\
\hline Prosocial behaviour & 0.79 & $5.97(2.36)$ & $4.73(2.83)$ & 0.12 & 0.51 \\
\hline \multicolumn{6}{|l|}{ Agency support factors } \\
\hline Caseworker quality & - & $2.30(1.19)$ & $2.45(1.29)$ & 0.69 & -0.12 \\
\hline Agency support satisfaction & 0.68 & $13.41(3.56)$ & $12.45(2.91)$ & 0.41 & 0.28 \\
\hline Training (number of courses) & - & $7.03(3.71)$ & $7.64(3.47)$ & 0.62 & -0.17 \\
\hline Monetary allowance satisfaction & - & $2.34(1.06)$ & $2.64(1.03)$ & 0.40 & -0.28 \\
\hline Respite (days) $\dagger$ & - & $3.38(4.31)$ & $3.64(3.98)$ & 0.55 & -0.07 \\
\hline Government agency satisfaction & - & $2.64(0.97)$ & $3.05(0.79)$ & 0.19 & -0.43 \\
\hline
\end{tabular}

Note. Unless otherwise indicated, group comparisons were conducted using $t$-tests. Effect sizes are Cohen's $d$ ( 0.20 is small, 0.50 is medium, 0.80 is large).

*Significant differences identified between groups, without correction.

$\dagger$ Group comparisons were performed using Mann-Whitney $U$ tests. Effect sizes are Clark-Carter's conversion to $r$ ( 0.10 is small, 0.30 is medium, 0.50 is large).

†roup comparisons of frequency data were examined using Fisher's exact tests. Effect sizes calculated using the continuity corrected Pearson $\chi^{2}$ value and are Cohen's $w$ ( 0.10 is small, 0.30 is medium, 0.50 is large).

${ }^{\mathrm{a}}$ The number of placements and number of children can vary due to sibling placements.

Table 2. Correlations of factors discriminating continuing placement and breakdown placement groups.

\begin{tabular}{|c|c|c|c|c|c|c|c|c|c|}
\hline & 1 & 2 & 3 & 4 & 5 & 6 & 7 & 8 & 9 \\
\hline 1. Placement match & 1 & & & & & & & & \\
\hline 2. Conflicts & $.37 * *$ & 1 & & & & & & & \\
\hline 3. Closeness & $-.60 * *$ & $-.44 * *$ & 1 & & & & & & \\
\hline 4. Cognitive empathy & -.11 & -.03 & $.34 * *$ & 1 & & & & & \\
\hline 5. Family support & -.11 & $-.32 * *$ & .11 & .04 & 1 & & & & \\
\hline 6. Caregiver satisfaction & $-.42 * *$ & $-.71 * *$ & $.50 * *$ & .01 & $.42 * *$ & 1 & & & \\
\hline 7. Satisfaction with role demands & -.19 & $-.47 * *$ & $.29 *$ & .21 & $.35 * *$ & $.51 * *$ & 1 & & \\
\hline 8. Partner relationship quality $(N=54)$ & -.21 & $-.47 * *$ & .18 & .08 & .21 & .22 & $.41 * *$ & 1 & \\
\hline 9. Child age at placement commencement & .17 & .06 & $-.27 *$ & .01 & -.10 & -.15 & -.04 & -.20 & 1 \\
\hline
\end{tabular}

$* * p<.01 . * p<.05$. 
Table 3. Summary of effects in the mediation model

\begin{tabular}{ccc}
\hline \multicolumn{1}{c}{ Effect } & Estimate & $95 \%$ confidence interval \\
\hline $\begin{array}{c}\text { Total effect } \\
\text { Relationship quality c } \\
\text { Direct effect } \\
\begin{array}{c}\text { Relationship quality c' } \\
\text { Indirect effect } \\
\text { Conflicts } a b\end{array}\end{array}$ & $0.29^{*}$ & {$[0.07,0.51]$} \\
\hline
\end{tabular}

*Significant at $p<.05 .{ }^{\dagger}$ Bias corrected bootstrap confidence interval (95\%).

Table 4. Model coefficients for a mediation model of conflicts with the child on the association between relationship quality with a carer's partner and the level of satisfaction with the role demands of being a carer.

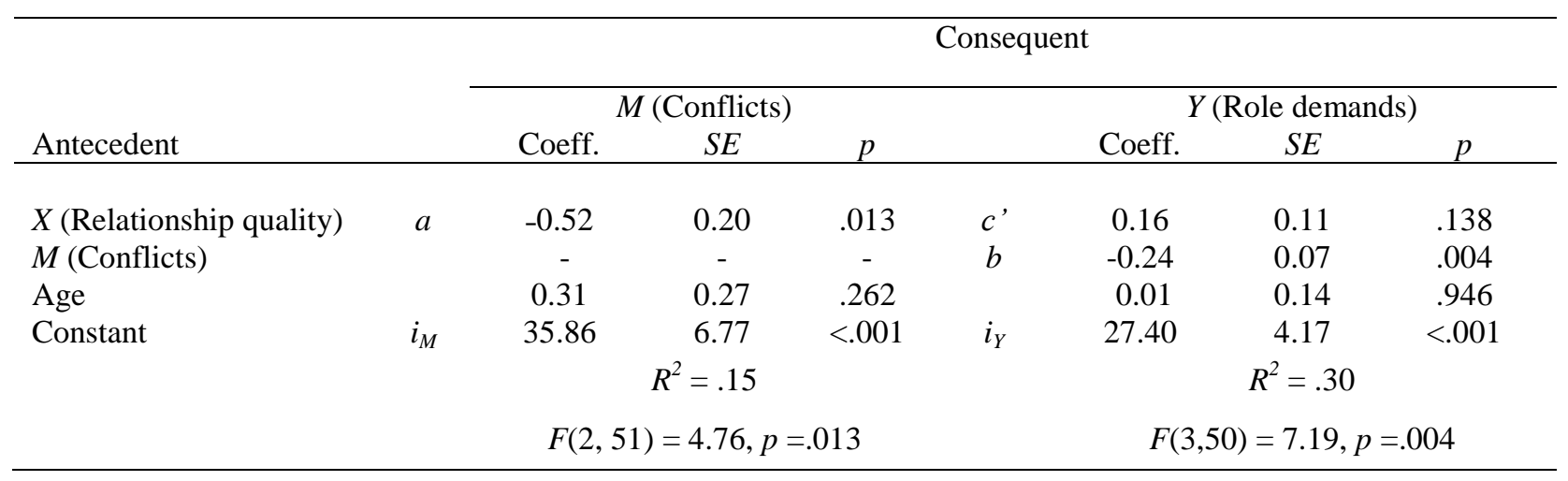

